\title{
ANALISIS ANGGARAN PARSIAL DAN PREFERENSI PETANI TERHADAP KARAKTER BEBERAPA VARIETAS UNGGUL PADI \\ LAHAN SAWAH TADAH HUJAN DI KABUPATEN SAMBAS (STUDI KASUS DESA MATANG DANAU, KEC.PALOH)
}

\author{
Rusli Burhansyah $^{* 1}$, Dina Omayani Dewi ${ }^{1}$ \\ ${ }^{1}$ BPTP Kalimantan Barat \\ Jalan Budi Utomo no.45 Siantan Hulu, Pontianak \\ Email: rbuhansyah@gmail.com
}

\begin{abstract}
Problems with rainfed lowland rice cultivation in Sambas Regency include; the level of productivity is still low and the attack of blast disease and planthopper pests. Therefore, the introduction of new high-yielding varieties that have high productivity and resistant to blast disease and planthopper pests. Besides that, new improved varieties are in accordance with the tastes of the local community. This study aims to determine the analysis of the financial feasibility and preferences of farmers to the character of superior varieties of rice in rain-fed rice fields. The field research was carried out on 10 hectares of farmers' land and survey in Matang Danau village, Paloh sub-district. Research time is from April to August 2018. Respondents were 30 ethnic Malay cooperative farmers. Data collected included input and output data of rice farming, farmer characteristics, plant morphology. Data collection through observation and interviews with farmers. Observations were made on growth in the field and just before harvest. From the results of the study showed that the new superior variety of Inpari 41 was feasible to be cultivated with MBCR 1.49 with additional gross revenue of $R p$ 5,435,000 $(39.92 \%)$ with again on the total cost of $R p$ 1,252,940 (22.45\%) of the variety Cilosari. Farmers like the Inpari 41 variety because based on plant type, plant height, panicle length, number of productive tillers, level of production, resistance to pests and diseases, grain loss rate, grain color, aspects that get attention in developing rice in rainfed lowland are vegetative growth, grain form, quality of rice, rice texture, and taste of rice that are favored by local farmers as information for breeders in assembling new superior varieties of rainfed lowland rice.
\end{abstract}

Keywords: Financial feasibility, Preference, New high yielding varieties, Rainfed lowland

\section{PENDAHULUAN}

Teknologi yang berperan penting dalam peningkatan hasil padi yakni varietas unggul. Kontribusi nyata varietas unggul terhadap peningkatan produksi padi nasional antara lain tercermin dari pencapaian swasembada beras pada tahun 1984. Varietas sebagai salah satu komponen produksi telah memberikan sumbangan sebesar 56\%, oleh karena itu salah satu titik tumpu utama peningkatan produksi padi adalah perakitan dan perbaikan varietas unggul baru (Chairuman, 2013). Varietas padi unggul berperan penting dalam meningkatkan produksi, mengendalikan hama penyakit tanaman, dan menekan pengaruh buruk kondisi lingkungan tumbuh. Dibandingkan dengan teknologi produksi lainnya, varietas unggul lebih cepat diterima petani karena lebih mudah diimplementasikan dan harganya relatif murah (Rahayu, 2012).

Sebagai komponen produksi, varietas memberikan kontribusi terbesar dalam meningkatkan produksi padi. Hasil penelitian Sularno et al, (2011) varietas unggul baru Inpari 13 dapat meningkatkan produktivitas 33,92\% dan meningkatkan keuntungan bersih $56,57 \%$.. Pergiliran varietas yang dilakukan oleh petani telah mampu meningkatkan produksi dan memberikan nilai tambah ekonomi bagi petani di Jawa Barat (Ruskandar et al., 2007). Oleh 
sebab itu pengembangan/penyebaran VUB pada tingkat petai untuk mencapai tujuan pemerintah tersebut.

Kabupaten Sambas merupakan salah satu sentra padi di Provinsi Kalimantan Barat. Luas panen padi kabupaten Sambas sekitar 101.502 ha atau sekitar $23.45 \%$ dari luas panen provinsi Kalimantan Barat sekitar 433.944 ha. Sedangkan produtkivitas padi kabupaten Sambas masih rendah yakni 2,8 ton/ha dibandingkan dengan provinsi 2,9 ton/ha. (BPS Provinsi Kalbar, 2018). Permasalahan yang dihadapi petani padi kabupaten Sambas antara lain; rendahnya produktivitas padi, pemupukan belum optimal, penyakit blast dan wereng. Salah satu solusi untuk meningkatkan produktivitas padi yakni penggunaan vareitas unggul baru.

Teknologi Budidaya Padi di Kecamatan Paloh cukup baik. Petani sudah menanam 2 kali. Pertama pada Musim Hujan dengan padi local dengan umur 6-8 bulan. Untuk musim kemarau antara lain; Air Tenggulang, Inpara 3 dan Cilosari. Untuk pemakaian pemupukan antara lain; NPK $100 \mathrm{~kg} / \mathrm{ha}$, Urea $50 \mathrm{~kg} / \mathrm{ha}$, SP36 $50 \mathrm{~kg} / \mathrm{ha}$, sedangkan $\mathrm{KCl}$, pupuk Organik dan Kapur tidak pernah diberikan. Budidaya padi dengan cara tugal, legowo 4:1, semai dengan ditugal, pemupukan persemaian dengan urea, jumlah tanaman per lubang 4-5. 1 ha diperlukan $50 \mathrm{~kg}$ dengan produksi 3 ton. Untuk serangan hama dan penyakit, dari hasil peringkat yang terpenting berturut-turut antara lain; wereng coklat, walang sangit, ulat tanah, orong-orong, keong mas dan blast. Lokasi rawan kekeringan dan kebanjiran. MK dimulai bulan April dan MH bulan Oktober (Burhansyah et al., 2017)

Salah satu penyebaran VUB yang telah dilakukan oleh BPTP Kalbar di kawasan perbatasan kabupaten Sambas mengadakan display VUB di sejumlah lokasi yang strategis yakni di desa Matang Danau. Desa Matang Danau merupakan salah satu sentra padi di Kecamatan Paloh. Varietas unggul baru yang diperkenalkan melalui Display VUB tahun 2018 adalah Inpari 16, 22, 30 dan 41). Upaya ini untuk memperkenalkan VUB secara langsung kepada responden sehingga mereka dapat melihat secara langsung keragaman varietas padi baru yang dikenalnya. Sehingga mereka dapat menentukan pilihan untuk pergiliran varietas sesuai preferensinya.

Suatu teknologi pertanian dapat diterima oleh petani harus memenuhi kriteria kelayakan teknis artinya teknologi tersebut mudah diterapkan. Selain kelayakan teknis juga kelayakan finansial, artinya teknologi tersebut menguntungkan bila dibandingkan teknologi sebelumnya. Kriteria yang terakhir yakni kelayakan sosial, artinya secara sosial teknologi tersebut diterima oleh masyarakat.

Tingkat kesukaan responden terhadap varietas padi sangat penting untuk diketahui. Pemulia padi mendapatkan gambaran karakteristik padi yang disukai responden/petani dan dapat memulai pekerjaannya untuk menghasilkan padi dengan karakter yang disukai tersebut. Dilain pihak, produsen dapat mengetahui varietas yang akan diproduksi dalam jumlah banyak dan jumlah sedikit sehingga produsen tidak merugi akibat tidak terjualnya produk. Programprogram bantuan benih dapat dilaksanakan secara efektif dan efisien karena varietas yang cocok diapang (baik secara agroekologi namun secara preferensi disukai oleh petani). Varietas yang dapat diterima oleh khalayak pengguna harus ditentukan secara cepat, karena berpacu dengan perkembangan kondisi lapang serta program diseminasi yang harus dilakukan dengan cepat dan tepat. 
Berdasarkan permasalahan tersebut di atas maka upaya-upaya untuk meningkatkan produktivitas padi sawah tadah hujan melalui pengenalan varietas unggul baru (VUB) padi. Yang menjadi pertanyaan apakah varietas unggul baru tersebut layak secara finansial dan petani menyukainya. Untuk menjawab pertanyaan tersebut diperlukan suatu penelitian. Penelitian ini bertujuan untuk mengetahui kelayakan finansial dan preferensi petani terhadap varietas unggul baru padi di Kabupaten Sambas (studi kasus desa Matang Danau, Kecamatan Paloh)

\section{METODE PENELITIAN}

Bahan yang dipakai dalam penelitian ini meliputi benih padi Inpari 16, Inpari 22, Inpari 30, Inpari 41, serta benih cilosari. Sedangkan pupuk yang digunakan meliputi Pupuk non organik meluputi urea dan npk. Pestisida terdiri dari herbisida, fungsida, rodentisida, nematisida. Penelitian tidak menggunakan rancangan percobaan. Percobaan menggunakan demfarm dengan luas 10 hektar. Penelitian dilaksanakan mulai bulan April 2018 sampai Agustus 2018. Kegiatan demfarm padi ini dilaksanakan di desa Matang Danau, Kecamatan Paloh, Kabupaten Sambas yang melibatkan petani 40 orang kelompok tani Angin Surga.

Tahapan penelitian preferensi dibagi ke dalam dua tahapan, yaitu (1) penilaian petani terhadap keragaman tanaman yang meliputi tipe dan tinggi tanaman, anakan produktif, panjang malai, umur tanaman, dan ketahanan terhadap hama dan penyakit, dan (2) penilaian terhadap produktivitas dan mutu antara lain; tingkat produksi, tingkat kerontokan gabah, bentuk gabah dan warna gabah.

\section{Metode Analisis}

\section{Analisis Data}

Analisis data dapat dilakukan melalui analisis efektivitas penerapan teknologi dari yang menerapkan teknologi introduksi dibandingkan teknologi petani. Teknologi Petani terdiri dari varietas Cilosari, pengolahan lahan tanpa olah lahan, pengelolaan hara pupuk urea $100 \mathrm{~kg} / \mathrm{ha}$, NPK $200 \mathrm{~kg} / \mathrm{ha}$, sistem tanam tegel, umur pindah dan jumlah bibit 14 hari, 2-3 bibit, pengendalian gulma mekanis dan kimia, pengendalian hama penyakit secara terpadu, panen dan prosesing menggunakan sabit gerigi. Sedangkan teknologi introduksi varieta unggul baru inpari 16, inpari 22, inpari 30 dan inpari 41, pengolahan lahan tanpa olah tanah, pengelolaan hara yakni pupuk urea $100 \mathrm{~kg} / \mathrm{ha}$, NPK $200 \mathrm{~kg} / \mathrm{ha}$ dan pupuk biotara $25 \mathrm{~kg} / \mathrm{ha}$, sistem tanam jajar legowo 4:1 $(20 \times 15 \times 40 \mathrm{~cm})$, umur pindah bibit 14 hari dan 2-3 bibit, pengendalian gulma mekanis dan kimia, pengendalian hama dan penyakit secara terpadu, panen menggunakan sabit gerigi.

Analisis dengan menggunakan Uji t. Uji t dua sampel independen (independentsampel t Test) digunakan untuk membandingkan selisih dari dua purata (mean) dari dua sampel yang independent dengan asumsi data terdistribusi normal. Bentuk uji hipotesis satu sisi (one side atau one tailed test) untuk sisi bawah (lower tailed) dengan hipotesis (Uyanto, 2009):

$H_{o}: \mu_{1} \geq \mu_{2} \operatorname{atauH}_{0}: \mu_{1}-\mu_{2} \geq 0$ 


\section{Analisis Anggaran Parsial}

Peubah yang diamati meliputi kuantitas dan harga input yang digunakan (pupuk anorganik, pupuk organik), hasil cabai segar, keuntungan kotor dan bersih serta tingkat pengembalian marginal. Data-data yang diperoleh dianalisa dengan metode analisis anggaran parsial (Horton D, 1982) sebagai berikut:

$\sigma N I=\sigma T R-\sigma V C$

$R=\sigma N I / \sigma V C$

Keterangan:

INI $=$ Penerimaan bersih marjinal

TR $=$ Penerimaan total marjinal

$\mathrm{VC} \quad=$ Biaya peubah marjinal

$\mathrm{R} \quad=$ Tingkat pengembalian marjinal

Pengambilan keputusan

$\mathrm{R}<1=$ perlakuan tidak memberikan nilai tambah

$\mathrm{R}>1$ = perlakuan memberikan nilai tambah

Untuk mengetahui tingkat optimum penggunaan input produksi dapat dilakukan analisis melalui cara yang lebih sederhana dan praktis, yaitu melalui analisis anggaran parsial (partial budget analysis). Analisis anggaran parsial merupakan analisis pendapatan dan biaya dari suatu alternatif kegiatan dengan menghitung perubahan yang terjadi dari pendapatan dan biaya yang diakibatkan oleh kegiatan tersebut atau yang disebut juga dengan laju penerimaan bersih marjinal (marginal rate of return, MRR atau incremental benefit cost ratio, IBCR), yakni rasio pertambahan penerimaan bersih dengan tambahan biaya variabel dari setiap perlakuan. Secara matematis diformulasikan sebagai berikut ( Sudana et al,, 1999).

$M R R=\frac{R}{C}=\frac{R(n+1)-{ }^{-}{ }_{11}}{C(n+1)-C_{11}}$

Dalam hal ini, Rn adalah pendapatan bersih ke $\mathrm{n}$ dan $\mathrm{Cn}$ merupakan biaya variabel ke n. Analisis anggaran parsial bisa juga digunakan untuk mengetahui seberapa besar nilai tambah (sebagai indikator kelayakan ekonomi) yang diperoleh dari penerapan paket teknologi yang dianjurkan (introduksi).

\section{Analisis Preferensi}

Pengujian dilakukan terhadap responden secara subjektif dengan uji indra (Haryadi, 2015). Pengujian dilakukan dengan memperlihatkan penampilan varietas unggul baru padi Inpari 16, Inpari 22, Inpari 30 dan Inpari 41 kepada petani responden. Petani menjawab pertanyaan yang disajikan dalam kuesioner. Data yang telah terkumpul ditabulasi, kemudian dianalisis menggunakan skoring (Tabel 1) 
Tabel 1. Preferensi petani terhadap morfologi tanaman dan mutu hasil beberapa varietas unggul padi sawah tadah hujan Desa Matang Danau, Kecamatan Paloh, Kabupaten Sambas, 2018

\begin{tabular}{clrll}
\hline $\begin{array}{c}\text { Interval } \\
\text { skor }(\%)\end{array}$ & \multicolumn{1}{c}{ Preferensi } & $\begin{array}{c}\text { Bobot } \\
(\%)\end{array}$ & Jumlah Petani & Nilai Skor(\%) \\
\hline $84,01-100$ & Sangat suka & 20 & $\mathrm{n}$ & $\mathrm{n} \times$ bobot \\
$68,01-84$ & Suka & 20 & $\mathrm{n}$ & $\mathrm{n} \times$ bobot \\
$52,01-68$ & Cukup suka & 20 & $\mathrm{n}$ & $\mathrm{n} \times$ bobot \\
$36,01-52$ & Tidak suka & 20 & $\mathrm{n}$ & $\mathrm{n} \times$ bobot \\
$20,00-36$ & Sangat tidak suka & 20 & $\mathrm{n}$ & $\mathrm{n} \times$ bobot \\
\hline
\end{tabular}

Nilai skor yaitu bobot dikali jumlah petani untuk setiap varietas. Preferensi total dari setiap varietas merupakan skor rata-rata dari semua karakter yang dimiliki varietas tersebut. Jika nilai tertinggi berarti varietas tersebut paling disukai. Preferensi petani terhadap karakter varietas adalah rata-rata semua nilai skor untuk semua varietas yang diuji pada karakter yang sama. Jika nilai rata-rata karakter paling tinggi berarti karakter tersebut paling disukai.

Data preferensi petani didistribusikan pada kelas yang berbeda. Pemberian skor menggunakan skala Likert dengan lima kriteria antara lain; $5=$ sangat suka, $4=$ suka, $3=$ cukup suka, 2 = tidak suka dan 1 =sangat tidak suka. Kriteria tersebut memiliki interval yang besarnya ditentukan oleh rumus interval yang besarnya ditentukan oleh rumus interval kelas. Nilai skor ditampilkan dalam bentuk persentase (Nasution dan Barizi 1988 dalam Rina dan Koesrini 2016; Suharyanto dan Kariada 2011) dengan rumus:

$$
\text { Panjang Interval }=\frac{\% \text { Skor tertinggi }-\% \text { Skor terendah }}{\text { Jumlah interval kelas }}
$$

\section{HASIL DAN PEMBAHASAN}

\section{Kondisi Geografis dan Sosial Ekonomi Desa Matang Danau}

Luas wilayah dan besarnya jumlah penduduk Desa Matang Danau merupakan salah satu faktor pendukung dan potensi dalam melaksanakan otonomi Desa. Di samping itu, yang tak kalah pentingnya adalah tingkat partisipasi Masyarakat yang tinggi dalam membangun desa merupakan faktor yang paling utama dalam memajukan Desa (BPS Kabupaten Sambas, 2018).Desa Matang Danau Kecamatan Paloh memiliki wilayah 4.401 Ha. Yang terdiri dari; lahan pertanian tanaman padi $900 \mathrm{Ha}$, Perumahan dan Pekarangan 1,5 Ha lahan perkebunan Rakyat 1,75 Ha, Tanah wakaf, 13.339 Ha. Adapun batas-batas Desa Matang Danau Sebagai berikut : Sebelah Utara dengan Desa Laut Matuna. Sebelah Selatan dengan Desa Matang Segantar dan Mulia Kecamatan Teluk Keramat. Sebelah Barat dengan Desa Kalimantan Kecamatan Paloh dan Merabuan kec. Tangaran. Sebelah Timur dengan Desa Tanah Hitam (BPS Kabupaten Sambas, 2018). Desa Matang Danau merupakan desa yang terletak di Kecamatan Paloh, Kabupaten Sambas, Kalimantan Barat. Desa ini kemudian terdapat empat dusun, yaitu; Dusun Pantai Laut, Dusun Mariana, Dusun Perigi Nyatu dan Dusun Matang Putus. Menurut data BPS Penduduk Desa Matang Danau tahun 2016 berjumlah 4.265 Jiwa 
yang terdiri dari: Laki-laki 2.131 Jiwa dan Perempuan 2.134 Jiwa dan sebanyak 1.158 Kepala Keluarga. Mata pencaharian masyarakat Desa Matang Danau terdiri dari; Petani 3.490 Orang, Nelayan 42 Orang, Usaha industri sedang 10 0rang, Pedagang 54 Orang, PNS/TNI/POLRI 76 Orang. Swasta dan lainnya 17 Orang, Usaha industri kecil 3 orang, Buruh bangunan 18 orang, Pengangkutan 3 orang, perkebunan kecil 13 orang (BPS Kabupaten Sambas, 2018).

\section{Karakteristik Petani}

Rata-rata umur petani 46,4 tahun, dengan rata-rata lama pendidikan sekitar 7,27 tahun. Sedangkan pengalaman bertani sudah cukup lama sekitar 20,2o tahun. Tenaga kerja produktif 3 orang/KK, Luas lahan yang dimiliki petani sekitar 0,59 ha dengan luas lahan garapan 0,3 ha. Karakteristik petani dsajikan pada Tabel 2 dibawah ini

Tabel 2. Karakeristik petani padi pada agroekosistem lahan tadah hujan di desa Matang Danau, Kecamatan Paloh, Kabupaten Sambas, 2018

\begin{tabular}{lcc}
\hline \multicolumn{1}{c}{ Uraian } & Rata-rata & Kisaran \\
\hline Umur (th) & 46,4 & $33-56$ \\
Pendidikan (th) & 7,27 & $6-9$ \\
Pengalaman bertani (th) & 20,20 & $10-31$ \\
Tenaga kerja produktif (orang/KK) & 3 & $2-4$ \\
Luas lahan milik (ha) & 0,59 & $0,36-1$ \\
Luas lahan garapan & 0,39 & $0,24-0,67$ \\
\hline
\end{tabular}

Sumber: Analisis Data Primer, 2018

\section{Produktivitas padi}

Dari hasil panen didapatkan data produktivitas padi teknologi petani (Cilosari) dengan produksi padi introduksi teknologi (Inpari 16,22,30 dan 41) Rata-rata produktivitas cilosari $=3,11 \mathrm{t} / \mathrm{ha}$, Inpari 16=3,6 t/ha, Inpari 22=3,4 t/ha, Inpari 30=3,55 t/ha dan Inpari 41=4,2 t/ha. Dari hasil uji $\mathrm{T}$, terlihat nilai t hitung $(2,146,2,12,5,13)$ lebih tinggi dari t tabel $(2,030)$

Dari hasil perhitungan analisis anggara parsial, varietas yang direkomendasikan untuk dikembangkan hanya Inpari 41. Hal ini karena nilai MBCR di atas $1(1,49)$ pada Tabel 3 Inpari 41 mampu berproduksi 4,2 ton gkp/ha dengan mendapatkan keuntungan Rp. 8.634.997. Sedangkan Inpari 16,22 dan 30 tidak bisa direkomendasikan karena nilai MBCR dibawah 1. Menurut Lalu, et al., (2017) bahwa varietas-varietas padi yang direkomendasikan untuk padi sawah tadah hujan antara lain; Inpari 1, Inpari 10, Inpari 13, Inpari 18, Inpari 19, Inpari 20, Inpari 21, Inpari 22, Inpari 30, Inpari 32, Inpari 33, Inpari 38, Inpari 39, Inpari 40, Inpari 41, Inpari 42 dan Inpari 43. Kelebihan varietas Inpari 41 antara lain agak peka pada kekeringan, agak rentan terhadap WBC biotipe 1,2,3, agak tahan penyakit HDB strain III dan rentan strain IV dan VIII, rentan virus tungro, tahan penyakit blas ras 133 dan 173 (Jamil et al, 2015) Setelah melalui pengujian di beberapa lokasi diketahui Inpari 41 Tadah Hujan Agritan berpotensi menghasilkan 7,8 ton per hektar Gabah Kering Giling (GKG). Varietas Inpari 41 merupakan salah satu varietas yang toleran kekeringan (Sujinah dan Ali Jamil, 2016). 
Tabel 3. Analisis Anggaran Parsial Teknologi Introduksi Padi Sawah Tadah Hujan (Inpari 16, 22, 30 dan 41 vs Varietas Lokal) di Desa Matang Danau, MK 2018

\begin{tabular}{|c|c|c|c|c|c|}
\hline Uraian & $\begin{array}{c}\text { Teknologi } \\
\text { Petani (Varietas } \\
\text { Lokal) }\end{array}$ & $\begin{array}{l}\text { Introduksi } \\
\text { Teknologi } \\
\text { (Inpari 16) }\end{array}$ & $\begin{array}{l}\text { Introduksi } \\
\text { Teknologi } \\
\text { (Inpari 22) }\end{array}$ & $\begin{array}{l}\text { Introduksi } \\
\text { Teknologi } \\
\text { (Inpari 30) }\end{array}$ & $\begin{array}{l}\text { Introduksi } \\
\text { Teknologi } \\
\text { (Inpari 41) }\end{array}$ \\
\hline Input & 1.400 .000 & 4.445 .000 & 4.445 .000 & 4.445 .000 & 4.445 .000 \\
\hline Tenaga Kerja & 5.926 .000 & 7.920 .000 & 7.920 .001 & 7.920 .002 & 7.920 .003 \\
\hline Total biaya & 7.326 .000 & 12.365 .000 & 12.365 .001 & 12.365 .002 & 12.365 .003 \\
\hline $\begin{array}{l}\text { Output } \\
\text { Hasil }\end{array}$ & 2.700 & 3.600 & 3.400 & 3.550 & 4.200 \\
\hline $\begin{array}{l}\text { Harga gabah } \\
\text { (GKP) Rp/kg }\end{array}$ & 5000 & 5000 & 5000 & 5000 & 5000 \\
\hline Penerimaan & 13.500 .000 & 18.000 .000 & 17.000 .000 & 17.750 .000 & 21.000 .000 \\
\hline $\begin{array}{l}\text { Pendapatan } \\
\text { (Keuntungan) }\end{array}$ & 6.174 .000 & 5.635 .000 & 4.634 .999 & 5.384 .998 & 8.634 .997 \\
\hline $\mathrm{R} / \mathrm{C}$ & 1,84 & 1,46 & 1,37 & 1,44 & 1,70 \\
\hline $\mathrm{B} / \mathrm{C}$ & 0,84 & 0,46 & 0,37 & 0,44 & 0,70 \\
\hline MBCR & & 0,89 & 0,69 & 0,84 & 1,49 \\
\hline
\end{tabular}

Sumber: Analisis Data Primer, 2018

Dari penelitian pemupukan nitrogen dan perlakuan air Inpari 41 oleh Hikmah et al., ( 2017) diperoleh bahwa varietas Inpari 41 respon terhadap dosis pupuk $\mathrm{N}$ dan pengelolaan air. Produktivitas Inpari 41 mencapai 5,7 t/ha GKG.

\section{Varietas Unggul yang Disukai}

Preferensi petani terhadap varietas unggul padi yang diuji pada lahan sawah tadah hujan ditampilkan pada Tabel 5. Karakter pertumbuhan tanaman dan mutu hasil varietas unggul yang diintroduksikan perlu diketahui petani karena akan mempengaruhi keputusan untuk mengadopsi

Tingkat kesukaan petani terhadap karakter keragaman tanaman vareitas unggul padi berturut-turut adalah pada tipe tanaman, panjang malai, tinggi tanaman, umur tanaman, dan anakan produktif. Sementara tingkat kesukaan petani berturut-turut pada karakter tipe tanaman, tinggi tanaman, anakan produktif, panjang malai, umur tanaman dan anakan produktif. Dari data ini dapat diurutkan prioritas karakter tanaman yang paling disukai petani responden yaitu tipe tanaman, tinggi tanaman, panjang malai, dan anakan produktif.

\section{Preferensi Petani Terhadap Keragaan Tanaman Tipe Tanaman}

Tipe tanaman merupakan karakter yang paling diutamakan petani dalam menilai varietas karena menentukan bentuk tanaman (serak, tegak) yang dapat dinilai langsung di lapangan. Petani etnis Melayu Sambas sangat suka tipe tanaman varietas Inpari 41 dan 30. Selain itu mereka suka dengan varietas Inpari 16 dan Inpari 22. Penampilan tanaman seperti tumbuh tegak atau serak merupakan tipe tanaman. Padai varietas unggul Inpari umumnya 
dirakit dari tetua dengan tipe tanaman dan daun bendera tegak. Varietas yang memiliki tipe ini memungkin penetrasi dan distribusi cahaya lebih besar sampai ke bagian bawah secara merata, sehingga meningkatkan fotosintesis pada tanaman. Murchi et al, (2002) dalam Koesrini et al, (2017) melaporkan fotosintesis pada tanaman dengan kanopi daun tegak sekitar $20 \%$ lebih tinggi dibandingkan kanopi daun terkulai pada kondisi indeks luas daun tinggi.

\section{Tinggi Tanaman, Jumlah Anakan, Panjang Malai, Umur Tanaman Dan Ketahanan Terhadap Hama Dan Penyakit}

Petani etnis Melayu Sambas sangat menyukai postur tanaman varietas Inpari 41dan Inpari 30. Suka dengan varietas Inpari 16 dan Inpari 22. Varietas Inpari 41 dan 30 memiliki postur sedang (tinggi tanaman $<110 \mathrm{~cm}$ ), batang kokoh dan tegak, sehingga panen lebih mudah dibandingkan dengan varietas dengan postur tanaman yang lebih pendek maupun lebih terlalu tinggi. Tanaman tertinggi saat panen ditunjukkan oleh varietas Inpari $22(102,5 \mathrm{~cm})$ dan Inpari $16(101,3 \mathrm{~cm})$, sedangkan tanaman terendah ditunjukkan oleh varietas Inpari 30 $(100,3 \mathrm{~cm})$ dan Inpari $41(94,5 \mathrm{~cm})$. Berdasarkan penelitian IRRI (2014), tanaman Inpari $16,22,30$ dan 41 tergolong rendah $(<110 \mathrm{~cm})$.

Dari aspek jumlah anakan, petani Melayu Sambas menyukai Inpari 30 dan Inpari 41. Menurut pantauan petani, varietas tersebut memiliki jumlah anakan produktif 10-15 batang/rumpun, sedang menurut deskripsi varietas 10-20 batang/rumpun untuk varietas Inpari 30,18 batang/rumpun untuk varietas Inpari 41.Sedang varietas Inpari 16 batang/rumpun dan Inpari 22 batang/rumpun. Petani sangat menyukai varietas Inpari 30 dan Inpari 41 sangat menyukai pada panjang malai Inpari 30 dan 41. Petani juga menyukai Inpari 16 dan Inpari 22. Sebagian besar malai varietas Inpari termasuk tipe sedang yakni dengan panjang $20-30 \mathrm{~cm}$.

Petani sangat menyukai varietas Inpari 30 dan Inpari 41. Kedua varietas ini berumur di bawah 120 hari. Varietas Inpari 30 berumur 111 hari, varietas Inpari 41 berumur 114 hari. Sedangkan varietas Inpari 16 dan 22 petani suka juga karena umur varietas Inpari 16 dan Inpari 22 berumur sekitar 118 hari. Dari segi ketahanan hama dan penyakit tanaman, petani menyukai varietas Inpari 41 karena cukup tahan dari serangan penyakit blast dan hama wereng. Sedangkan varietas Inpari 30, Inpari 22 dan Inpari 16 petani cukup suka. Ketiga varietas tersebut masih terserang penyakit blas dan hama wereng.

Tabel 4. Preferensi petani terhadap penampilan vegetatif varietas unggul baru padi

\begin{tabular}{|c|c|c|c|c|c|c|c|c|}
\hline \multirow[b]{2}{*}{ Varietas } & \multirow[b]{2}{*}{$\begin{array}{c}\text { Tipe } \\
\text { tanaman }\end{array}$} & \multirow[b]{2}{*}{$\begin{array}{l}\text { Tinggi } \\
\text { tanaman }\end{array}$} & \multirow[b]{2}{*}{$\begin{array}{l}\text { Anakan } \\
\text { produktif }\end{array}$} & \multicolumn{3}{|c|}{ Preferensi petani (\%) } & \multirow[b]{2}{*}{ Skor } & \multirow[b]{2}{*}{ Kategori } \\
\hline & & & & $\begin{array}{l}\text { Panjang } \\
\text { malai }\end{array}$ & $\begin{array}{l}\text { Umur } \\
\text { tanaman }\end{array}$ & $\begin{array}{l}\text { Ketahana } \\
n \\
\text { hama dan } \\
\text { penyakit }\end{array}$ & & \\
\hline Inpari 16 & 77,60 & 72,00 & 65,60 & 60,00 & 60,80 & 56,80 & 65,467 & $\mathrm{CS}$ \\
\hline Inpari 22 & 72,00 & 71,20 & 67,20 & 71,20 & 72,80 & 60,00 & 69,067 & $\mathrm{~S}$ \\
\hline Inpari 30 & 87,20 & 89,60 & 92,00 & 87,20 & 96,00 & 65,66 & 86,277 & SS \\
\hline Inpari 41 & 87,20 & 90,40 & 92,00 & 90,40 & 88,80 & 92,00 & 90,133 & SS \\
\hline Rata-rata & 81,00 & 80,80 & 79,20 & 77,20 & 79,60 & 68,62 & 77,74 & $\mathrm{~S}$ \\
\hline
\end{tabular}

Sumber: Analisis Data Primer, 2018 


\section{Preferensi terhadap produksi, mutu gabah, warna gabah, tingkat produksi, tingkat kerontokan gabah}

Preferensi petani terhadap produksi (tingkat produksi, tingkat kerontokan gabah) dan mutu gabah (bentuk gabah dan warna gabah) disajikan pada Tabel 6. Berdasarkan nilai skor tertinggi terlihat tingkat kesukaan petani terhadap karakter mutu hasil berturut-turut adalah warna gabah, tingkat produksi, tingkat kerontokan gabah, dan bentuk gabah. Petani responden memiliki preferensi sangat suka terhadap warna gabah varietas Inpari 41. Warna gabah varietas Inpari 41 adalah kuning jerami. Sedangkan varietas Inpari 30 petani suka karena warna gabah kuning bersih. Untuk varietas Inpari 16 dan Inpari 22 petani sama-sama kurang suka karena warna gabah kuning tidak bersih. Tetapi menurut deskripsi, warna gabah Inpari 16 dan Inpari 22 sama-sama kuning bersih. Petani responden sangat suka dengan varietas Inpari 41 karena produktivitas tinggi. Dari hasil demplot di lapangan varietas ini mampu berproduksi 4,2 t/ha. Sedangkan varietas Inpari 30 berproduksi 3,5 t/ha. Petani responden kurang suka terhadap varietas Inpari 16 dan 22 karena produktivitas masih di bawah Inpari 41.

Petani sangat menyukai varietas Inpari 41 karena tingkat kerontokan gabah mudah, sedang varietas Inpari 30 suka karena tingkat kerontokan gabah sedang. Petani kurang suka dengan varietas Inpari 16 dan 22 karena tingkat kerontokan tahan (Tabel 5). Pengembangan lahan sawah tadah hujan untuk usahatani padi dihadapkan pada kendala kemasan tanah, cekaman air (kekeringan), serangan penyakit blast. Oleh karena itu, varietas yang dikembangkan pada lahan sawah tadah hujan ke depan memiliki selain memiliki tipe tanaman serak-tegak, postur tanaman sedang, jumlah anakan 16-19 batang, malai panjang, umur genjah-sedang, gabah ramping, tingkat kerontokan mudah, tahan kekeringan dan tahan penyakit blast.

Tabel 5. Preferensi petani terhadap penampilan generatif varietas unggul baru padi

\begin{tabular}{|c|c|c|c|c|c|c|}
\hline Varietas & $\begin{array}{l}\text { Tingkat } \\
\text { produksi }\end{array}$ & $\begin{array}{c}\text { Tingkat } \\
\text { kerontokan } \\
\text { gabah }\end{array}$ & $\begin{array}{c}\text { Bentuk } \\
\text { gabah }\end{array}$ & $\begin{array}{l}\text { Warna } \\
\text { gabah }\end{array}$ & Skor & Kategori \\
\hline Inpari 16 & 56,8 & 63,2 & 61,6 & 65,6 & 61,80 & $\mathrm{CS}$ \\
\hline Inpari 22 & 59,2 & 53,6 & 52,8 & 56 & 55,40 & $\mathrm{CS}$ \\
\hline Inpari 30 & 78,4 & 73,6 & 72 & 72,8 & 75,80 & $\mathrm{~S}$ \\
\hline Inpari 41 & 84,4 & 83,2 & 84 & 89,6 & 83,80 & SS \\
\hline Rata-rata & 69,8 & 68,4 & 67,6 & 71 & 69,2 & $\mathrm{~S}$ \\
\hline
\end{tabular}

Sumber: Analisis Data Primer, 2018

Pada umumnya petani dalam budidaya padi sawah tadah hujan belum menggunakan pupuk organik. Pupuk organik bisa berasal dari kotoran hewan (pupuk kendang sapi, kambing maupun ayam) maupun jerami padi. Dalam memenuhi kebutuhan unsur nitrogen, petani menggunakan pupuk urea dan NPK. Penggunaan pupuk anorganik dalam jangka panjang akan mengakibatkan antara lain; Polusi air, sindrom bayi biru, kontaminasi zat pengotor, ketergantungan terhadap pupuk anorganik, Hilangnya unsur mikro, konsumsi energi tinggi, kontribusi terhadap perubahan iklim, dampak terhadap Mikoriza, eutrofikasi, peningkatan keasaman tanah, pencemaran udara.

Hasil penelitian Hartatik et al, (2015) bahwa pemupukan 75\% dari dosis rekomendasi NPK dan 2 t/ha pupuk organik granul pada tanaman padi varietas IR-64 berproduksi di atas 7 
ton/ha. Pemberian pupuk organik dalam budidaya padi sawah tadah hujan bertujuan untuk memperbaiki kesuburan fisik, kimia, dan biologi tanah serta mengefisiensikan penggunaan pupuk an-organik.

Penggunaan konsorsium Bacillus cereus dan Pseudomonas aeruginosa potensi yang sangat baik dalam menghambat pertumbuhan cendawan patogen tanaman padi Pyricularia grisea secara in vivo penyebab penyakit blast padi. Kemampuan Bacillus cereus, Pseudomonas aeruginosa, serta konsorsium dalam menghambat pertumbuhan Pyricularia grisea cenderung lebih baik daripada perlakuan dengan menggunakan fungisida (Kesuma et al, 2016)

\section{KESIMPULAN}

Produksi varietas Unggul Baru Inpari 41 (4,2 t/ha) secara ekonomi layak diusahakan untuk meningkatan produktivitas padi lahan sawah tadah hujan. Tambahan biaya sekitar 41,85\% dan tambahan keuntungan sekitar 34,92\% menghasilkan tambahan keuntungan sekitar Rp 1.252.949 atas biaya total dengan nilai MBCR sekitar 1,30.

Inpari 41 paling disukai petani untuk karakter tipe tanaman, tinggi tanaman, jumlah anakan, panjang malai, umur tanaman dan ketahanan terhadap penyakit, tingkat produksi, tingkat kerontokan gabah, bentuk gabah, warna gabah.

Dalam pengembangan varietas padi pada lahan sawah tadah hujan di daerah Kabupaten Sambas ke depan maka varrietas-vaeritas baru harus mempunyai keunggukan antara lain memiliki pertumbuhan (vegetatif), bentuk gabah, mutu beras, tekstur nasi, dan rasa nasi yang disukai petani setempat, serta toleran kemasaman tanah, keracunan besi, dan cekaman air, tahan penyakit blast dan wereng. Informasi ini diharapkan menjadi masukan bagi pemulia tanaman dalam merakit varietas unggul baru padi di lahan sawah tadah hujan.

\section{DAFTAR PUSTAKA}

BPS Provinsi Kalimantan Barat. 2018. Kalimantan Barat dalam Angka 2018. BPS Kalimantan Barat.

BPS Kabupaten Sambas. 2018. Kabupaten Sambas Dalam Angka 2018. BPS Kabupaten Sambas.

Burhansyah, R, A. Subekti, G.C. Kifli, Azri, K. Supriyadi, A. Musyafak. 2017. Laporan Akhir Dukungan Inovasi Teknologi Di Daerah Perbatasan Kalimantan Barat. BPTP Kalbar.

Chairuman, N. 2013. Kajian Adaptasi Beberapa Varietas Unggul Baru Padi Sawah Berbasis Pendekatan Tanaman Terpadu Di Dataran Tinggi Tapanuli Utara Provinsi Sumut. Jurnal online Pertanian Pasca Sarjana FP USU. 1(1):47-54

Darsani YR dan Koesrini. 2018. Preferensi Petani terhadap Karakter Beberapa Varietas Unggul Padi Lahan Rawa Pasang Surut. Penelitian Pertanian Tanaman Pangan 2(2): 85-94.

Hardiyanti, F.S. 2003. Perencanaan Wilayah Dengan Pendekatan Spasial dan Analisis Ambang Batas (Studi Kasus Wilayah Perbatasan Kabupaten Sambas). Prosiding Lokakarya Nasional. Menuju Pengelolaan Sumberdaya Willayah Berbasis Ekosistem Untuk Mereduksi Potensi Konflik Antar Daerah. UGM. 
Hikmah, ZM., N Agustiani, S.Sriyana, K.Hayashi.2017. Karakteristik Keragaan Agronomis Varietas Padi Sawah Tadah Hujan Pada Pemupukan Nitrogen dan Perlakuan Air. Jurnal Lahan Suboptimal: Journal of Suboptimal Lands ISSN: 2252-6188 (Print), ISSN: 2302-3015 (Online, www.jlsuboptimal.unsri.ac.id) Vol. 6, No.2: 176-184 Oktober 2017.

Horton, D. 1982. Partial Budgeet Analysis For On Farm Potato Research. Tehnical Information Bulletin 16. June. International Potato Center. Lima. Peru. 19 pp

Indrasari, Purwaningsih, E Apriyat, dan S D Ardhiyanti. 2016. Preferensi Konsumen pada Beras Berlabel Jaminan Varietas untuk Hipa 8, Ciherang dan Inpari 13. Penelitian Pertanian Tanaman Pangan 35(3): 173-180

Jamil A, Satoto, P Sasmita, Y Baliadi, A Guswara dan Suhana. 2015. Deskripsi Varietas Unggul Baru Padi. Badan Penelitian dan Pengembangan Pertanian. Kementerian Pertanian.

Kesuma, HI, Zuraidah dan S.Kamal. 2016. Pengendalian Penyakit Blas yang disebabkan oleh Cendawan Patogen Pyricularia Grisea Dengan Aplikasi Bakteri Pada Tanaman Padi (Oryza Sativa) Var.Inpari 15. Prosiding Seminar Nasional Biotik 2016. ISBN:978602-18962-9-7

Koesrini dan K.Anwar.2017. Pengelolaan Air, Bahan Organik dan Varietas Adaptif Untuk Meningkatkan Hasil Padi Di Lahan Rawa Pasang Surut. Berita Biologi 16(1): 39-46.

Las.I,D.Soetopo,I.Inounu,T.Sudaryanto,Hermanto,K.Subagyono,H.Syahbuddin,

.N.Cakrabawa, S.Mardianto dan T.Alihamsyah. 2017. Grand Design Pengembangan Lumbung Pangan Berorientasi Eskpor di Wilayah Perbatasan. Sekretariat Jenderal Kementerian Pertanian.

Lalu M. Zarwazi, Y.Nugraha, A.P.V.Yuningsih. 2017. Rekomendasi Pengelolaan Lahan Berbasis Agroekosistem dan Kesesuaian Lahan Untuk Pengembangan Peningkatan Produksi Padi. Balai Besar Penelitian Tanaman Padi, Balitbangtan,

Manikmas, MO.. 2010. Respon Produsen dan Konsumen terhadap Varietas Unggul Padi Beras Merah dalam Menciptakan Peluang Pasar. Penelitian Pertanian Tanaman Pangan 29(2) : 89-97 Pusat Penelitian dan Pengembangan Tanaman Pangan

Ningsih R dan K Nafisah. 2014. Preferensi Konsumen Kalimantan Selatan Terhadap Beras Dan Rasa Nasi Varietas Unggul Rina D.Ningsih Dan Khairatun Nafisah Prosiding Seminar Nasional "Inovasi Teknologi Pertanian Spesifik Lokasi”, Banjarbaru 6-7 Agustus 2014 Balai Pengkajian Teknologi Pertanian (Bptp) Kalimantan Selatan

Rahayu, HSP. 2012. Preferensi Petani Kabupaten Donggala Terhadap Karakteristik Kualitas Dan Hasil Beberapa Varietas Unggul Baru Padi Sawah Farmer Preferences On Quality And Yield Characteristic Of New Paddy Varieties In Donggala District Widyariset, Vol. 15 No.2,: 293-3000

Rohaeni WR, A Sinaga, dan MI Ishaq. 2012. Preferensi Responden Terhadap Keragaan Tanaman Dan Kualitas Produk Beberapa Varietas Unggul Baru Padi. (Studi kasus dalam mendukung penyebaran vub padi sawah di Kabupaten Karawang). Informatika Pertanian. 21( 2): 97 - 103.

Rina Y dan Koesrini. 2016. Tingkat Adopsi Varietas Inpara dan Margasari di Lahan Pasang Surut. Agros 18(1):65-80.

Ruskandar, A., W.R.Rohaeni, M.I. Ishag, dan N.Sutrisna. 2012. Pendampingan P2BN Kabupaten Karawang. Balai Pengkajian Teknologi Pertanian Jawa Barat (Tidak dipublikasikan) 
Sudana, W., N.Ilham, D.K.S.Sadra, dan R.N.Suhaeti.1999. Metodologi Sosek. Metodologi Penelitian dan Demplot Sosial Ekonomi Pertanian. Badan Penelitian dan Pengembangan Pertanian.

Suharyanto dan Kariada. 2011. Kajian Adopsi Penerapan Teknologi Pupuk Organik Kascing Di Daerah Sentra Produksi Sayuran Kabupaten Tabanan. Jurnal Pengkajian dan Pengembangan Teknologi Pertanian 14(1): : 28-39.

Suhendrata T.E., Kushartani, dan Widarto. 2008. Preformasi varietas unggul baru dalam mendukung peningkatan produksi beras di Kabupaten Batang. Jawa Tengah. Prosiding Seminar Nasional Padi: 683-688.

Sujinah dan Ali Jamil. 2016. Mekanisme Respon Tanaman Padi terhadap Cekaman Kekeringan dan Varietas Toleran. Iptek Volume 11.No.1. Hal.1-8. Pusat Penelitian Tanaman Pangan. Badan Penelitian dan Pengembangan Pertanian.

Sularno, J.Handoyo dan Nurhalim. 2011. Peran Inovasi Teknologi Varietas Unggul Baru Terhadap Peningkatan Pendapatan Petani. Hal.91-96. Buku I.Prosiding Seminar Nasional Pemberdayaan Petani Melalui Inovasi Teknologi Spesifik Lokasi. BB2TP, STTP Magelang. ISBN.978-979-98579-7-2.

Syamsiah S, R Nurmalina Dan , A Fariyanti . 2015. Analisis Sikap Petani Terhadap Penggunaan Benih Padi Varietas Unggul Di Kabupaten Subang Jawa Barat (Attitude Analysis Of Farmers Toward Using Rice Seed High Yielding Varieties In Subang Regency West Java) AGRISE Volume XVI No. 3 Bulan Agustus 2015 ISSN:

Uyanto, S. 2009. Pedoman Analisis Data dengan SPSS. Yogjakarta. Graha Ilmu. 